The University of Maine

DigitalCommons@UMaine

Maine-Syracuse Longitudinal Papers

Maine-Syracuse Longitudinal Study

1998

\title{
Idiopathic intracranial hypertension and orthostatic edema may share a common pathogenesis
}

Deborah L. Friedman

David H. P. Streeten

Follow this and additional works at: https://digitalcommons.library.umaine.edu/

longitudinal_papers

\section{Repository Citation}

Friedman, Deborah L. and Streeten, David H. P., "Idiopathic intracranial hypertension and orthostatic edema may share a common pathogenesis" (1998). Maine-Syracuse Longitudinal Papers. 65.

https://digitalcommons.library.umaine.edu/longitudinal_papers/65 


\title{
Idiopathic intracranial hypertension and orthostatic edema may share a common pathogenesis
}

\author{
Deborah I. Friedman, MD; and David H.P. Streeten, MB, DPhil, FRCP
}

\begin{abstract}
Article abstract-Our aim was to determine the frequency of orthostatic edema (OE) in patients with idiopathic intracranial hypertension (IIH). We evaluated 30 women with IIH for evidence of OE by comparing sodium and water excretion in the recumbent and standing postures and morning and evening body weights. Data were compared with findings in 30 women with $\mathrm{OE}, 22$ weight-matched obese normal subjects, and 20 lean normal subjects. The effect of treatment with diuretics or diuretics plus sympathomimetic agents was compared. Seventy-seven percent of IIH patients had evidence of peripheral edema and $80 \%$ had significant orthostatic retention of sodium or water. Excretion of a standard saline load and of a tap water load was significantly impaired in the upright posture in the IIH and OE patients compared with the lean and obese normal subjects. Diuretic therapy induced weight loss (up to $9 \mathrm{~kg}$ ) and decreased mean weight gain from morning to evening in 5 of 12 patients treated. In seven patients also treated with diuretics plus sympathomimetic drugs, the diuretic-induced morning weight loss and morning to evening weight gain were both significantly improved with the addition of sympathomimetic agents. Therapy reduced the frequency or severity of headaches in seven patients and reduced papilledema in four patients who received no other concurrent treatment for IIH. The orthostatic retention of sodium and water and the consequent edema is very similar in IIH and OE patients, suggesting a common pathogenesis for both disorders. Diuretic therapy, dietary salt and water restriction, and planned periods of recumbency merit study as a treatment for these patients.
\end{abstract}

NEUROLOGY 1998;50:1099-1104

Idiopathic intracranial hypertension (IIH), also known as pseudotumor cerebri, is associated with cerebral venous sinus thrombosis and a variety of drug therapies and systemic disorders that have no apparent common pathogenic mechanism. In most patients, the syndrome is idiopathic. IIH typically occurs in obese women of childbearing age. The chance observation that 3 of 169 patients with idiopathic edema had IIH prompted the present investigation to determine whether patients with IIH might have the same disorder of salt or water excretion in the upright posture that is characteristic of the most common form of idiopathic edema, orthostatic edema $(\mathrm{OE})^{1.2}$

Methods. We investigated 30 women with IIH, aged 14 to 50 years, between 1982 and 1994 to determine whether there was evidence of dependent edema after prolonged standing; the magnitude of weight gain from morning to evening, a clinical hallmark of orthostatic fluid retention; evidence of orthostatic changes in urinary sodium, creatinine, and water excretion during standardized oral loading with dilute saline and with tap water; and the response of body weight, headache severity and frequency, and papilledema to a vigorous diuretic program. The results were compared with findings in normal obese female volunteers (NSO; $n=22$ ), frequently matched by weight to the patients, and lean female volunteers (NSL; $n=20$ ) and in 30 women with symptomatic $\mathrm{OE}$ seen consecutively and selected because they had excessive orthostatic retention of sodium or of a water load or both. ${ }^{1}$

We determined evidence of fluid retention by a medical history and a standardized questionnaire inquiring about the presence of edema at the ankles or in the legs, fingers, abdomen, and the periorbital tissues. Patients indicated whether the edema was more noticeable upon awakening in the morning or before retiring at night. We examined the patients to determine the presence of pitting edema at the ankles and pretibial areas and the hands (judged by the ability of the patients to remove rings from their fingers without difficulty).

Subjects kept records of their body weights obtained on a bathroom scale after emptying the bladder immediately after arising each morning and before retiring each evening for at least 2 weeks. These records were continued during diuretic therapy.

The diagnosis of IIH was confirmed by verifying the

From the Departments of Neurology and Ophthalmology (Dr. Friedman), and Medicine and the Section of Endocrinology (Dr. Streeten), SUNY Health Science Center, Syracuse, NY.

Supported by the Wahrsager Foundation, the National Institute of Aging (AGO3055), a Clinical Research Center Grant (RR229) from the Division of Research Facilities and Resources, U.S.P.H.S., SUNY Health Science Center Clinical Research Unit, National Eye Institute (EY 09552), and the Hendricks Fund for Medical Research, SUNY Health Science Center, Syracuse.

Presented in part at the annual meetings of the North American Neuro-Ophthalmology Society, Big Sky, MT, February 1993 and Durango, CA, February 1994; and the Endocrine Society, Las Vegas, NV, June 1993.

Received January 23, 1997. Accepted in final form October 23, 1997

Address correspondence and reprint requests to Dr. Deborah I. Friedman, Department of Neurology, SUNY Health Science Center, 750 East Adams Street, Syracuse, NY 13210. 


\begin{tabular}{|c|c|c|c|c|c|c|c|c|}
\hline & \multicolumn{2}{|c|}{$\begin{array}{l}\text { Normal, lean } \\
\quad(n=20)\end{array}$} & \multicolumn{2}{|c|}{$\begin{array}{l}\text { Normal, obese } \\
\quad(n=22)\end{array}$} & \multicolumn{2}{|c|}{$\begin{array}{l}\text { Orthostatic edema } \\
\qquad(\mathrm{n}=30)\end{array}$} & \multicolumn{2}{|c|}{$\begin{array}{c}\text { Idiopathic intracranial } \\
\text { hypertension } \\
(\mathrm{n}=30)\end{array}$} \\
\hline & Mean & $95 \% \mathrm{CI}$ & Mean & $95 \% \mathrm{CI}$ & Mean & $95 \% \mathrm{CI}$ & Mean & $95 \% \mathrm{CI}$ \\
\hline Age (y) & 32.8 & $28.0-37.6$ & $41.2^{*}$ & $37.3-45.1$ & 37.0 & $31.9-42.1$ & 30.0 & $26.3-33.7$ \\
\hline Weight (kg) & $55.7^{*}$ & $52.8-58.6$ & 94.5 & $85.8-103.2$ & $75.0^{*}$ & $68.3-81.7$ & 96.6 & $86.4-106.8$ \\
\hline Height $(\mathrm{cm})$ & 159.6 & $156.9-162.3$ & 160.4 & $157.9-162.9$ & 163.2 & $158.9-167.5$ & 162.6 & 159.7-165.5 \\
\hline $\mathrm{BMI}\left(\mathrm{kg} / \mathrm{m}^{2}\right)$ & $22.0^{*}$ & $21.2-22.8$ & 37.0 & $33.3-40.7$ & $27.5^{*}$ & $24.8-30.2$ & 36.2 & $32.3-40.1$ \\
\hline
\end{tabular}

${ }^{*} p<0.05$ in comparison with idiopathic intracranial hypertension patients.

presence of papilledema, documenting elevated spinal fluid pressure ( $\geq 250 \mathrm{~mm} \mathrm{H}_{2} \mathrm{O}$ ), confirming normal CSF composition, and excluding a space-occupying lesion by $\mathrm{CT}$ or MRI. Twenty-five patients were examined by a neuroophthalmologist (D.I.F.) and had threshold automated perimetry, stereoscopic viewing of the optic nerves, and fundus photography. All patients without IIH had normal-appearing optic nerves by direct ophthalmoscopy (D.H.P.S.).

Orthostatic change in urinary excretion was assessed by measuring the urinary output of sodium, creatinine, and water in two separate procedures. The "posture test" comprised these urinary measurements during salt-loading with $150 \mathrm{~mL}$ of $0.14 \%$ saline solution given by mouth every 30 minutes while the patient remained recumbent for 4 hours (except for voiding) and then while standing for the next 2 hours. The salt solution was administered on an empty stomach starting at 8:00 to 8:30 AM at least a week after cessation of any antecedent diuretic treatment or restriction of sodium intake. ${ }^{1}$ The orthostatic changes were expressed as the excretion of sodium, creatinine, and water in the standing 2-hour period divided by their excretion during the second half of the recumbent 4-hour period.

On a subsequent or previous day, urinary volume was measured hourly for 4 hours after an oral water load of 20 $\mathrm{mL} / \mathrm{kg}$ (maximum, $1,500 \mathrm{~mL}$ ) ingested on an empty stomach with patients standing for 4 hours starting at 8:00 to 8:30 AM. Urinary volume measurements were repeated after the same water load on another occasion while the patients remained supine for 4 hours (except for hourly voidings). The occurrence of nausea or vomiting during either of these procedures invalidated the test because of the known inhibitory effect of these stimuli on diuresis. ${ }^{3}$

Response to diuretic therapy, including chlorthalidone $50 \mathrm{mg}$ and spironolactone (Aldactone, Searle, Chicago, IL) $100 \mathrm{mg}$ daily, was measured by twice-daily body weights and records kept by the patients of the frequency and severity of headaches and any side effects of the therapy. Assessment of the effects of treatment on body weight, subjective symptoms, and severity of papilledema was made by at least one author 1 to 2 and 6 months after the initiation of diuretic therapy. Eleven patients had stereoscopic fundus photographs taken at follow-up examinations to document the degree of papilledema.

In 15 patients, the effects of adding sympathomimetic drugs (dextroamphetamine 10 to $40 \mathrm{mg}$ daily or phentermine 15 to $30 \mathrm{mg}$ daily) were determined on body weight, frequency and severity of headaches, and severity of papill- edema. The duration of follow-up was 0 to 214 months (mean, 46 months).

All studies on patients and healthy subjects were performed after the individuals had read and signed a consent document approved by our Institutional Review Board for the Protection of Human Subjects.

Statistical methods. The distribution of each variable was examined for the four groups of patients. Means, SEs, and $95 \%$ CIs were calculated using the $t$ distribution. ${ }^{4}$ Pooled variances from three groups (IIH, OE, NSO) were used to calculate the SEs of the differences between the means of these groups and their respective $95 \%$ CIs. Student's $t$-tests were used to assess the difference between IIH and other patients. The effects on body weights of diuretics alone and the same diuretics in the same doses together with sympathomimetic drugs were evaluated with paired $t$-tests in the seven IIH patients in whom both sets of data were obtained. Alpha was set at 0.05 , twotailed.

Results. Clinical findings. Table 1 shows the mean ages, weights, and heights of the four groups of subjects. Mean weight and body mass indices were significantly different in IIH and OE patients, as in IIH and NSL patients. Mean height was similar in the four groups. Mean weight gain from morning to evening was very similar in the IIH and OE patients but significantly greater $(p<0.01)$ in IIH and $O E$ patients than in normal subjects $(0.46 \pm 0.04 \mathrm{~kg}){ }^{4}$

All but one IIH patient had frequent headaches. Several patients commented that their headaches were worst in the morning. The IIH patients resembled the $\mathrm{OE}$ patients clinically in that 11 noticed periorbital edema upon awakening in the morning and 15 observed swelling of their fingers that necessitated removal of their rings at night. A few patients experienced abdominal swelling toward the end of the day. Seventeen IIH patients either noticed pedal edema or showed pitting edema at the ankles or in the pretibial areas on physical examination that was usually mild but sometimes moderately severe, especially when they were seen in the late afternoon. Thus, evidence of edema was present in 23 of $30 \mathrm{IIH}$ patients $(77 \%)$. All patients with $\mathrm{OE}$ had demonstrable peripheral edema, which was their main complaint. The normal obese patients had neither subjective nor objective evidence of peripheral edema.

Recumbent blood pressure was normal in all IIH patients except one whose hypertension was associated with the clinical and biochemical findings of central Cushing's 


\begin{tabular}{|c|c|c|c|c|}
\hline & $\begin{array}{l}\text { Normal, lean } \\
\quad(n=20)\end{array}$ & $\begin{array}{l}\text { Normal, obese } \\
\quad(n=22)\end{array}$ & $\begin{array}{l}\text { Orthostatic edema } \\
\qquad(\mathbf{n}=30)\end{array}$ & $\begin{array}{c}\text { Idiopathic } \\
\text { intracranial } \\
\text { hypertension } \\
(\mathbf{n}=30)\end{array}$ \\
\hline \multicolumn{5}{|l|}{ Urine volume $(\mathrm{mL} / 30 \mathrm{~min})$} \\
\hline Recumbent & $176 \pm 7$ & $144 \pm 11$ & $183 \pm 10$ & $135 \pm 9$ \\
\hline Standing & $72 \pm 5$ & $57 \pm 4$ & $29 \pm 3$ & $34 \pm 4$ \\
\hline Standing/recumbent $\%$ & $41 \pm 3$ & $39 \pm 4$ & $16 \pm 2$ & $25 \pm 4$ \\
\hline CIs standing/recumbent $\%$ & $35-47$ & $35-50$ & $13-19^{*}$ & $17-34^{*}$ \\
\hline \multicolumn{5}{|l|}{ Urine $\mathrm{Na}(\mathrm{mEq} / 30 \mathrm{~min})$} \\
\hline Recumbent & $5.8 \pm 0.7$ & $6.0 \pm 0.6$ & $8.7 \pm 0.8$ & $5.7 \pm 0.6$ \\
\hline Standing & $3.2 \pm 0.4$ & $3.0 \pm 0.3$ & $1.6 \pm 0.3$ & $1.6 \pm 0.2$ \\
\hline Standing/recumbent $\%$ & $55 \pm 4.2$ & $50 \pm 4.3$ & $18 \pm 1.4$ & $28 \pm 1.9$ \\
\hline CIs standing/recumbent $\%$ & $46-64$ & $41-58$ & $16-21 *$ & $24-32 *$ \\
\hline \multicolumn{5}{|l|}{ Urine creatinine $(\mathrm{mg} / 30 \mathrm{~min})$} \\
\hline Recumbent & $27.2 \pm 1.1$ & $39.1 \pm 3.3$ & $35.5 \pm 1.9$ & $39.7 \pm 1.9$ \\
\hline Standing & $24.8 \pm 0.8$ & $30.1 \pm 2.4$ & $22.2 \pm 1.2$ & $28.1 \pm 1.6$ \\
\hline Standing/recumbent $\%$ & $91.2 \pm 2.3$ & $77.0 \pm 6.0$ & $62.5 \pm 3.6$ & $70.8 \pm 3.8$ \\
\hline CIs standing/recumbent $\%$ & $86-96$ & $65-90$ & $55-70 \dagger$ & $64-80 \dagger$ \\
\hline
\end{tabular}

${ }^{*} p<0.05$ for the difference between this reference group when compared with both lean and obese groups.

$\dagger p<0.05$ for the difference between this reference group when compared with the lean group only.

syndrome and one who was hypotensive in recumbency $(84 / 72 \mathrm{~mm} \mathrm{Hg})$, with a further fall in blood pressure to $68 / 64 \mathrm{~mm} \mathrm{Hg}$ after standing for 3 minutes. Orthostatic tachycardia was present in five patients. ${ }^{1}$ There was no evidence of congestive heart failure or of renal disease except in one patient who had anasarca due to the nephrotic syndrome. We diagnosed hyperparathyroidism in one patient, but parathyroidectomy had no effect on her IIH.

Papilledema was present in all patients; it was frequently more severe in one eye than the other and was unilateral in two patients. Retinal hemorrhages were visible in three patients. Three patients had the radiologic features of an empty sella.

Measurements of renal function while recumbent and standing. Postural changes in excretion during sodium loading. During dilute $(0.14 \%)$ sodium chloride loading ( $150 \mathrm{~mL}$ per half hour), renal excretion was normal, with urinary sodium and water output closely approximating or exceeding intake during the last 2 hours of the 4 hours in recumbency in all four groups (table 2). During the subsequent 2 hours in the standing posture, the mean rates of water, sodium, and creatinine excretion fell to some extent in all four groups.

The most discriminating index of these orthostatic changes was the ratio of standing/recumbent excretion rates (see table 2). Postural changes in excretion were similar in IIH and OE patients. The ratio of standing/ recumbent urine volume was significantly lower in patients with $\mathrm{IIH}$ and $\mathrm{OE}$ than in normal or lean patients (figure 1). Moreover, both IIH and OE patients had a lower ratio of standing/recumbent urine creatinine than normal lean patients. There was no significant difference in abnor- mal orthostatic water excretion between the $\mathrm{OE}$ and IIH patients (figure 2).

Three of nine IIH patients whose sodium excretion in the salt-loading study was normal excreted the water load subnormally in the upright posture. In this respect, these three patients were similar to a subgroup of OE patients who manifested orthostatic water (but not sodium) retention. ${ }^{2}$ Therefore, $21 \mathrm{IIH}$ patients had excessive orthostatic $\mathrm{Na}$ retention and three were solely orthostatic water retainers, so that $80 \%$ of the 30 patients had a significant orthostatic disorder of urinary excretion.

Effects of diuretic therapy. Because 23 of $30 \mathrm{IIH}$ patients $(77 \%)$ had clinical evidence of edema and excessive orthostatic retention of administered sodium or water, diuretic therapy was prescribed for all IIH patients. Initially, $50 \mathrm{mg}$ chlorthalidone daily was used in 13 patients because of its prolonged duration of activity together with $100 \mathrm{mg}$ spironolactone daily (Aldactone) and a potassium supplement (Micro K, Robins, Richmond, VA; 10 $\mathrm{mEq}$ tid) if hypokalemia occurred. Triamterene or hydrochlorothiazide/triamterene was later substituted for spironolactone in six patients. In 7 of these 13 and 8 other patients, a sympathomimetic drug, either sustainedrelease dextroamphetamine (10 to $40 \mathrm{mg}$ daily) or phentermine (15 to $30 \mathrm{mg}$ daily), was used with the same diuretics. Eighteen patients had been treated with 250 to $1,000 \mathrm{mg}$ acetazolamide per day (Diamox, Lederle Labs/ Wyeth Ayerst Labs, Philadelphia, PA) with stable body weight for many weeks. This treatment was not discontinued when the diuretics or the sympathomimetics were started and had no detectable effect on weight loss. Adequate recording of morning and evening body weights, with confirmation of weights during subsequent morning office visits, was possible in 19 of 30 patients. 


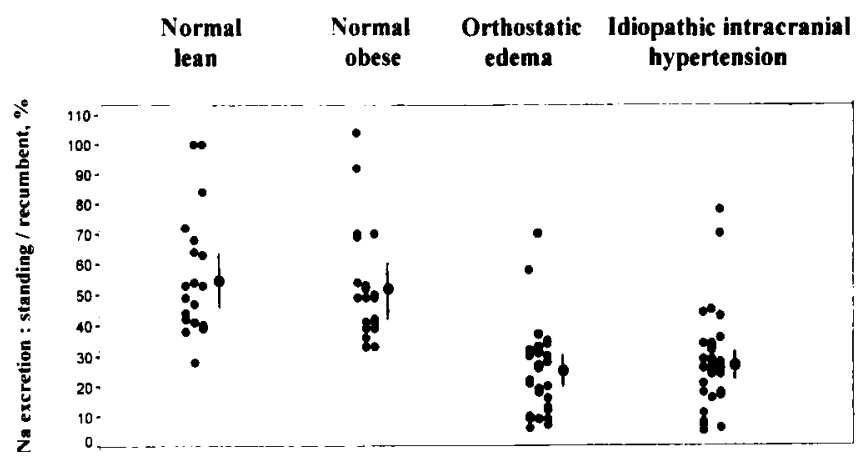

Figure 1. Orthostatic sodium excretion expressed as a percentage of recumbent sodium excretion during intake of $\mathrm{NaCl} 0.14 \%$ solution, $150 \mathrm{~mL}$ per half hour, in four groups of subjects. Orthostatic sodium excretion was subnormal ( $<33 \%$ of recumbent excretion) in 21 of 30 patients with IIH, and sodium excretion in these patients (28 \pm 1.9; CI, 24 to $32 \%$ ) was highly significantly below that found in the 22 obese normal subjects (50 $44.3 ; C I, 41$ to $58 \% ; \mathrm{p}<0.01$ ) but not significantly different from the findings in the $O E$ patients $(25 \pm 2.6 ; C I, 20$ to $31 \%)$. $\phi=$ Mean and $95 \%$ CI.

Table 3 shows that morning weights changed by +2 to $-9 \mathrm{~kg}$ during the first 2 to 6 weeks of diuretic therapy in 13 patients. Their mean weight loss was $1.8 \pm 0.9 \mathrm{~kg}$ (not significant, $p>0.05$ ). In the 15 patients treated with diuretic and sympathomimetic drug therapy, mean morning weights fell in 2 to 6 weeks by 0 to $18 \mathrm{~kg}(3.6 \pm 1.1 \mathrm{~kg}, p<$ 0.01 ). Mean weight gain from morning to evening was reduced by diuretics alone from a baseline mean of $2.0 \pm$ $0.34 \mathrm{~kg}$ by $0.5 \pm 0.2 \mathrm{~kg}$. With diuretic and sympathomimetic drugs, mean weight gain from morning to evening fell from $1.6 \pm 0.3 \mathrm{~kg}$ by $0.8 \pm 0.2 \mathrm{~kg}(p<0.01)$. Only seven patients received adequate treatment (for at least 2 weeks) both on diuretics alone and on diuretics and sympathomimetic therapy (see table 3 ). In these seven patients, the mean morning weight actually rose by $0.10 \pm 0.59 \mathrm{~kg}$ during treatment with diuretics alone. With a combination of diuretics and sympathomimetics, the mean morning weight fell by $3.06 \pm 0.82 \mathrm{~kg}$, a difference that was statistically significant ( $p=0.015$ ). The change in morning weight was greater for patients receiving both diuretics and sympathomimetics than for patients on diuretics alone (see table 3). This was also true for the change in weight from morning to evening; the reduction in weight gain was more evident in patients receiving both therapies than in those patients taking diuretics alone.

Side effects of therapy included lightheadedness, headaches, and secondary amenorrhea, requiring reduction in the chlorthalidone dosage or a change from spironolactone to triamterene therapy in three patients. Hypokalemia required supplemental potassium therapy despite the potassium-retaining actions of spironolactone in four patients. Those patients whose weight fell by more than $2 \mathrm{~kg}$ during therapy had improvement in their edema-related discomfort.

It was difficult to assess the effectiveness of this treatment on IIH. In general, the course of IIH varies considerably between patients, some of whom improve after the initial diagnostic LP. Several patients required other interventions before or during the treatment period that in-

$\begin{array}{ccc}\text { Normal } & \text { Normal } & \begin{array}{c}\text { Orthostatic } \\ \text { odema }\end{array}\end{array}$

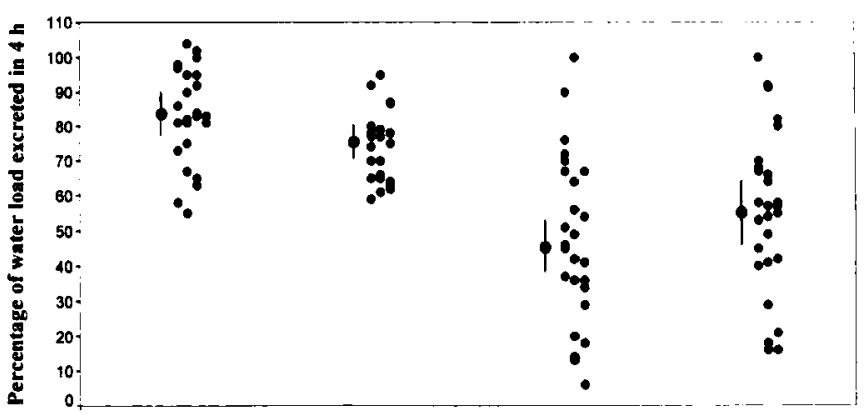

Figure 2. Water load tests. Percentages of water load (20 $\mathrm{mL} / \mathrm{kg}$ ) excreted while standing for 4 hours in four groups of subjects. Water excretion was subnormal $(<55 \%)$ in 13 of 27 patients with IIH and was significantly lower in the IIH patients (55.3 $\pm 4.5 ; \mathrm{CI}, 46$ to $65 \%)$ than in the obese normal subjects $(74.0 \pm 2.2 ; C I, 70$ to $79 \% ; \mathrm{p}<0.01) . \phi=$ Mean and $95 \% \mathrm{Cl}$.

cluded acetazolamide ( $n=18)$, furosemide $(n=8)$, digoxin ( $n=7$ ), lumboperitoneal shunt $(n=6)$, and optic nerve sheath decompression $(n=3)$. Reduction in the frequency or severity of headaches was volunteered by seven patients who did not receive additional treatments that might influence their condition. Papilledema improved in four patients who did not receive other forms of therapy (D.I.F.)

Discussion. There are many shared characteristics between patients with $\mathrm{IIH}$ and those with $\mathrm{OE}$. The presence of pretibial or ankle edema in the late afternoon is demonstrable in most women with $\mathrm{IIH}$ and in those with OE. The orthostatic defect in excretion of administered sodium and water in the two groups of patients differed from changes in normal subjects, suggesting a common pathogenetic mechanism. Additional features that are shared by these disorders are the striking diuresis and loss of weight that follows the administration of diuretics and the significant reduction in abnormal weight gain from morning to evening-a hallmark of $\mathrm{OE}$-when sympathomimetic drugs are added to the therapeutic regimen (see table 3 ). Whether or not this results from stimulation of vasoconstriction by norepinephrine released in response to these drugs is not known. Norepinephrine has also been implicated in CSF regulation in animals, inducing a $48 \%$ reduction in CSF production. ${ }^{5,6}$ This effect would be expected to be beneficial if it occurred in patients with IIH.

The possibility that excessive orthostatic transudation from the capillaries, predominantly in the lower limbs, in both disorders might also involve cerebral vasculature during recumbency in patients with IIH is worthy of consideration and is consistent with the observation that headaches were often more severe upon awakening than at other times in several of our patients with IIH. A vascular etiology is plausible because cranial venous thrombosis and venous outflow obstruction have long been known to cause IIH.7.8 Moreover, cerebral venous sinus ob- 
struction has been demonstrated by venography and manometry in IIH patients with normal arteriography and MRI, suggesting the presence of occult cerebral venous pathology in some patients with IIH. ${ }^{9}$

Increased CSF pressure without ventriculomegaly in IIH suggests the possibility of interstitial brain edema. Although there is no reliable method of confirming the presence of interstitial edema in the brain, there is some indirect supporting evidence of brain edema in IIH patients. MRI has shown evidence of increased brain water content in adults but not in children with IIH. ${ }^{10-12}$ Although autopsy data are scarce, Sahs and Joynt ${ }^{13}$ reported interstitial edema in cortical biopsies in patients who underwent subtemporal decompression. However, their interpretation of the findings was not substantiated by review of the original histology, although interstitial edema is difficult to confirm histologically because of tissue changes during processing..$^{14}$ Moreover, cerebral edema was not found in two patients with IIH who died of unrelated causes or in three other IIH patients. ${ }^{14,15}$ Therefore, this issue remains controversial.

Abnormalities in vasopressin (AVP) have been implicated in both disorders. By inducing renal retention of water, AVP regulates water movement across biological membranes. Urinary excretion of AVP is excessive in patients with $\mathrm{OE}$ in the upright posture, a phenomenon that is corrected by the ingestion of ethanol, which inhibits AVP release. ${ }^{16}$ IIH has been postulated to arise from either an overproduction or malabsorption of CSF. AVP in the CSF regulates brain water content and raises intracranial pressure by increasing water transudation from cerebral capillaries and in the choroid plexus epithelium and arachnoid villi. ${ }^{17-20}$ Thus, the high levels of AVP in the CSF that are present in patients with IIH might contribute to increased intracranial pressure in IIH. ${ }^{21-23}$ Therefore, although AVP regulation is under central control, independent from the peripheral circulation, abnormally high concentrations of AVP are

Table 3 Idiopathic intracranial hypertension patients: weight changes after therapy for 2-6 weeks

\begin{tabular}{|c|c|c|c|c|c|c|}
\hline \multirow[b]{2}{*}{ Patient } & \multicolumn{2}{|c|}{ Diuretics alone } & \multicolumn{2}{|c|}{ Diuretics and sympathomimetics } & \multirow[b]{2}{*}{$(4)-(2)$} & \multirow[b]{2}{*}{$(3)-(1)$} \\
\hline & (1) $\Delta$ Morning wt & (2) $\triangle \mathrm{AM}$ to PM wt & (3) $\Delta$ Morning wt & (4) $\triangle \mathrm{AM}$ to $\mathrm{PM} w \mathrm{wt}$ & & \\
\hline 1 & & & -3 & 0 & & \\
\hline 2 & 0 & 0 & -2 & -1 & -1 & -2 \\
\hline 3 & -3.5 & -1 & & & & \\
\hline 4 & 0 & & -1 & & & \\
\hline 5 & +1 & -0.5 & -4 & -0.5 & 0 & -5 \\
\hline 6 & -1 & -2 & -3.5 & -3 & -1 & -2.5 \\
\hline 7 & & & -18 & -1 & & \\
\hline 8 & +2 & 0 & -7 & -1 & -1 & -9 \\
\hline 10 & -3 & 0 & & & & \\
\hline 12 & & & -3 & -0.5 & & \\
\hline 14 & -3 & -1.5 & & & & \\
\hline 17 & +2 & 0 & 0 & -0.5 & -0.5 & -2 \\
\hline 18 & -6 & 0 & & & & \\
\hline 19 & -1 & 0 & -2 & -0.5 & -0.5 & -1 \\
\hline 20 & -9 & 0 & & & & \\
\hline 21 & -2 & -0.5 & -2.5 & -0.5 & 0 & -0.5 \\
\hline 24 & & & -1 & -2 & & \\
\hline 27 & & & -2 & 0 & & \\
\hline 28 & & & -1 & -1 & & \\
\hline 29 & & & -3.5 & 0 & & \\
\hline Mean & -1.8 & -0.5 & -3.6 & -0.8 & -0.57 & -3.1 \\
\hline SEM & 0.9 & 0.2 & 1.1 & 0.2 & 0.17 & 1.12 \\
\hline$t$ & & & & & 3.35 & 2.815 \\
\hline$p$ & & & & & 0.015 & $<0.03$ \\
\hline
\end{tabular}

Measurements represent mean changes in morning weight and in morning-to-evening weight increments during therapy with diuretics alone or with diuretics and sympathomimetics compared with corresponding weight measurements in each patient before treatment. The reductions in weight gain from morning to evening [(4) - (2)] and in morning weight [(3) - (1)] were significantly greater during treatment with diuretics and sympathomimetics than with diuretics alone $(p<0.015$ and 0.03 , respectively). 
common to both IIH and OE. Elevated AVP concentrations are probably responsible for the impaired excretion of a water load in OE that occurs also in IIH, as the present data have shown. ${ }^{24}$

Our findings suggest new forms of treatment that merit further study in patients with IIH. Obese patients are advised to lose weight as part of the initial treatment. Imbibing large volumes of water to induce satiety while dieting is probably counterproductive in these patients because it aggravates fluid retention. Because IIH patients retain sodium and water excessively in the upright posture, they should be advised to limit both sodium and water intake. Although a successful weight loss regimen incorporates diet and exercise, an exercise program is often difficult to initiate in patients with chronic headaches. The symptoms of $\mathrm{OE}$ are worsened by the upright posture and warm weather. Swimming has been a particularly effective form of exercise in some patients, probably because it combines a cool environment with recumbent posture. Finally, because many of these patients excrete water more efficiently while reclining, the diuretics used to treat this disorder may be more effective if taken shortly before a planned period of recumbency, as has been shown in OE. ${ }^{1}$

Although the patients were more comfortable after losing weight by diuresis, we were disappointed to find that the treatment did not consistently reduce the frequency or severity of headaches. Only four patients experienced improvement in their papilledema. The addition of sympathomimetic drugs diminished orthostatic fluid accumulation but did not always seem to improve the other manifestations of IIH. This might be due to the different innervation of the cerebral vasculature, which is characterized by autoregulation and relative resistance to alphaadrenergic vasoconstriction. ${ }^{5}$

\section{Acknowledgments}

We are grateful to Mary A.M. Rogers, $\mathrm{PhD}$, and Paul R. Sheehe, $\mathrm{PhD}$, for their assistance with the statistical analyses.

\section{References}

1. Streeten DHP. Orthostatic disorders of the circulation: mechanisms, manifestations and treatment. New York: Plenum, 1987:18, 19, 74,101-108, 117-119.

2. Streeten DHP, Dalakos TG, Souma M, Schletter FE, et al. Studies of the pathogenesis of idiopathic oedema: the roles of postural changes in plasma volume, plasma renin activity, aldosterone secretion rate and glomerular filtration in the retention of sodium and water. Clin Sci Mol Med 1973;45:347373 .
3. Anderson B, Lawson S. Inhibiting effect of emesis on water diuresis in the dog. Acta Physiol Scand 1954;32:19-27.

4. Gardner MJ, Altman DG, eds. Statistics with confidenceconfidence intervals and statistical guidelines. London: British Medical Journal, 1994:6-19.

5. Chien S. Cerebral blood flow and metabolism. In: Kandel ER, Schwartz JH, eds. Principles of neural science. New York: Elsevier, 1985:848-849.

6. Lindvall $\mathrm{M}$, Hardebo JE, Owman C. Barrier mechanisms for neurotransmitter monoamines in the choroid plexus. Acta Physiol Scand 1980;108:215-221.

7. Lam BL, Schatz NJ, Glaser JS, Bowen BC. Pseudotumor cerebri from cranial venous obstruction. Ophthalmology 1992;99: $706-712$.

8. Karahalios DG, Rekate HL, Khayta MH, Apostolides PJ. Elevated intracranial venous pressure as a universal mechanism in pseudotumor cerebri of varying etiologies. Neurology 1996; 46:198-202.

9. Cremer PD, Thompson C, Gjerris F, et al. Pseudotumor cerebri and venous hypertension. Neurology 1996;47:1602-1603.

10. Gideon P, S $\phi$ renson PS, Thomsen C, et al. Increased brain water self-diffusion in patients with idiopathic intracranial hypertension. Am J Neuroradiol 1995;16:381-387.

11. Connolly MB, Farrell K, Hill A, Flodmark O. Magnetic resonance imaging in pseudotumor cerebri. Dev Med Child Neurol 1992;34:1901-1904.

12. Sфrenson PS, Thomsen C, Gjerris F, et al. Increased brain water content in pseudotumor cerebri measured by magnetic resonance imaging of brain water self diffusion. Neurol Res $1989 ; 11: 160-164$.

13. Sahs AL, Joynt RJ. Brain swelling of unknown cause. Neurology 1956;6:791-803.

14. Wall M, Dollar JD, Sadun AA, Kardon R. Idiopathic intracranial hypertension. Lack of histologic evidence from cerebral edema. Arch Neurol 1995;52:141-145.

15. Greer M. Benign intracranial hypertension, VI. Obesity. Neurology $1965 ; 15: 382-388$.

16. Streeten DHP, Conn JW. Observations on the pathogenesis of idiopathic edema. J Clin Lab Med 1959;54:949-950.

17. Nilsson C, Lidvall-Axelsson M, Owman C. Neuroendocrine regulatory mechanisms in the choroid plexus-cerebrospinal fluid system. Brain Rev 1992;17:109-138.

18. Raichle ME, Grubb RL Jr. Regulation of brain water permeability by centrally-released vasopressin. Brain Res 1978;143: 191-194.

19. Noto T, Nakajima T, Saji Y, Ngawa Y. Effect of vasopressin on intracranial pressure. Endocrinol Jpn 1978;25:591-596.

20. Lisczak TM, Black PM, Foley L. Arginine vasopressin causes morphological changes suggestive of fluid transport in rat choroid plexus epithelium. Cell Tissue Res 1986;246:379-385.

21. Sфrenson PS, Hammer M, Gjerris F. Cerebrospinal fluid vasopressin in benign intracranial hypertension. Neurology 1982; 32:1255-1259.

22. Sфrenson PS, Gjerris F, Hammer M. Cerebrospinal fluid vasopressin and increased intracranial pressure. Ann Neurol 1984;15:435-440.

23. Seckl J, Lightman S. Cerebrospinal fluid neurohypophysial peptides in benign intracranial hypertension. J Neurol Neurosurg Psychiatry 1988;51:1538-1541.

24. Thibonnier MJ, Marchetti JP, Corvol PL, et al. Abnormal regulation of antidiuretic hormone in idiopathic edema. Am J Med 1979;67:67-73 